\title{
Central Neuronal Circuit Innervating the Lordosis-Producing Muscles Defined by Transneuronal Transport of Pseudorabies Virus
}

\author{
Derek Daniels, ${ }^{1}$ Richard R. Miselis, ${ }^{2,3}$ and Loretta M. Flanagan-Cato ${ }^{1,3}$ \\ Departments of ${ }^{1}$ Psychology and ${ }^{2}$ Animal Biology and ${ }^{3} / n s t i t u t e$ for Neurological Sciences, University of Pennsylvania, \\ Philadelphia, Pennsylvania 19104-6196
}

\begin{abstract}
The lordosis reflex is a hormone-dependent behavior displayed by female rats during mating. This study used the transneuronal tracer pseudorabies virus (PRV) to investigate the CNS network that controls the lumbar epaxial muscles that produce this posture. After PRV was injected into lumbar epaxial muscles, the time course analysis of CNS viral infection showed progressively more PRV-labeled neurons in higher brain structures after longer survival times. In particular, the medullary reticular formation, periaqueductal gray (PAG), and ventromedial nucleus of the hypothalamus (VMN) were sequentially labeled with PRV, which supports the proposed hierarchical network of lordosis control. Closer inspection of the PRV-immunoreactive neurons in the PAG revealed a marked preponderance of spheroid neurons, rather than fusiform or triangular morphologies. Furthermore, PRV-immunoreactive neurons were concentrated in
\end{abstract}

the ventrolateral column, rather than the dorsal, dorsolateral, or lateral columns of the PAG. Localization of the PRV-labeled neurons in the VMN indicated that the majority were located in the ventrolateral subdivision, although some were also in other subdivisions of the VMN. As expected, labeled cells also were found in areas traditionally associated with sympathetic outflow to blood vessels and motor pathways, including the intermediolateral nucleus of the spinal cord, the paraventricular hypothalamic nucleus, the red nucleus, and the motor cortex. These results suggest that the various brain regions along the neuraxis previously implicated in the lordosis reflex are indeed serially connected.

Key words: epaxial muscles; lordosis; motor control; periaqueductal gray; pseudorabies virus; sexual behavior; ventromedial hypothalamus
The lordosis reflex, a hormone-dependent behavior seen in female rodents during mating, has been a useful model for studying steroid action in the mammalian nervous system. Using traditional tract-tracing techniques, lesions and transections, and electrophysiology, researchers have identified a putative neural circuit controlling the execution of lordosis (Pfaff, 1980). Hierarchical command of this response is thought to emanate from estrogenand progesterone-sensitive neurons of the hypothalamic ventromedial nucleus (VMN), which innervate the periaqueductal gray (PAG), which in turn projects to premotor neurons in the medullary reticular formation (MRF). The premotor neurons of the reticular formation then influence the motor neurons of the spinal cord that innervate the lumbar epaxial muscles that produce the lordosis posture. Although this circuit has been identified in a stepwise manner, serial connectivity remains to be demonstrated.

Evidence for the role of the PAG is compelling but incomplete. For instance, lesions placed within the PAG reduce lordosis (Sakuma and Pfaff, 1979b). Conversely, electrical stimulation within the PAG facilitates lordosis (Sakuma and Pfaff, 1979a) and modulates the excitability of premotor medullary neurons relevant for lordosis (Cottingham et al., 1987). Additionally, inf usion of various neuroactive compounds into the PAG influences the

Received Oct. 29, 1998; revised Jan 19, 1999; accepted Jan. 24, 1999.

L.M.F.-C. is supported by National Institutes of Health Grant MH54712, and R.R.M. is supported by National Institutes of Health Grant GM27739. These results were reported in preliminary form at the 28th Annual Meeting of the Society for Neuroscience, November 1998 (Los Angeles, CA) and at the Annual Meeting of the Society for Behavioral Neuroendocrinology, 1998 (Atlanta, GA). We thank Drs. Yang and Zhao for their technical assistance and Ms. King for helpful comments on this manuscript.

Correspondence should be addressed to Derek Daniels, Department of Psychology, University of Pennsylvania, 3815 Walnut Street, Philadelphia, PA 19104-6196. Copyright (C) 1999 Society for Neuroscience 0270-6474/99/192823-11\$05.00/0 lordosis response (Harlan et al., 1983; Riskind and Moss, 1983; Floody et al., 1986; Dudley and Moss, 1988). However, the PAG is not a homogenous structure but, rather, contains distinct anatomical subdivisions (Beitz, 1985) and is functionally organized in longitudinal columns along the rostrocaudal axis (Bandler et al., 1991; Murphy et al., 1995; Rizvi et al., 1996). The identity of a lordosis-relevant column in the PAG remains a source of controversy, with studies reporting the involvement of the dorsal (Sakuma and Pfaff, 1979b; Morrell and Pfaff, 1982; Dornan et al., 1990; Tetel et al., 1993), dorsolateral (Sakuma and Pfaff, 1983; Richmond and Clemens, 1986), lateral (Harlan et al., 1983; Cottingham et al., 1987; Akesson et al., 1994), ventrolateral (Arendash and Gorski, 1983; Lonstein and Stern, 1998), and ventral (Uphouse et al., 1992) portions of the PAG. The neurons of the PAG also have been categorized by specific neuronal morphologies (Beitz and Shepard, 1985), although little is known about the functional significance of these morphological profiles and their role in lordosis. Previous anatomical approaches have not resolved these issues, in part because conventional tracers are not transported by functionally selected populations.

In this report the descending limb of the lordosis reflex was multisynaptically traced using the $\alpha$-herpesvirus pseudorabies virus (PRV), which is transported more rapidly in the retrograde direction (Card et al., 1990). This technique provided the opportunity to study higher-order neurons within the lordosisproducing circuit with confidence that they are linked to the relevant muscles. The time course of virus propagation into the CNS verified the existing model of a hierarchical organization of the control of the lordosis reflex and provided support for the serial connectivity of the previously identified nodes of the network. In addition, an analysis of the distribution and morphology 

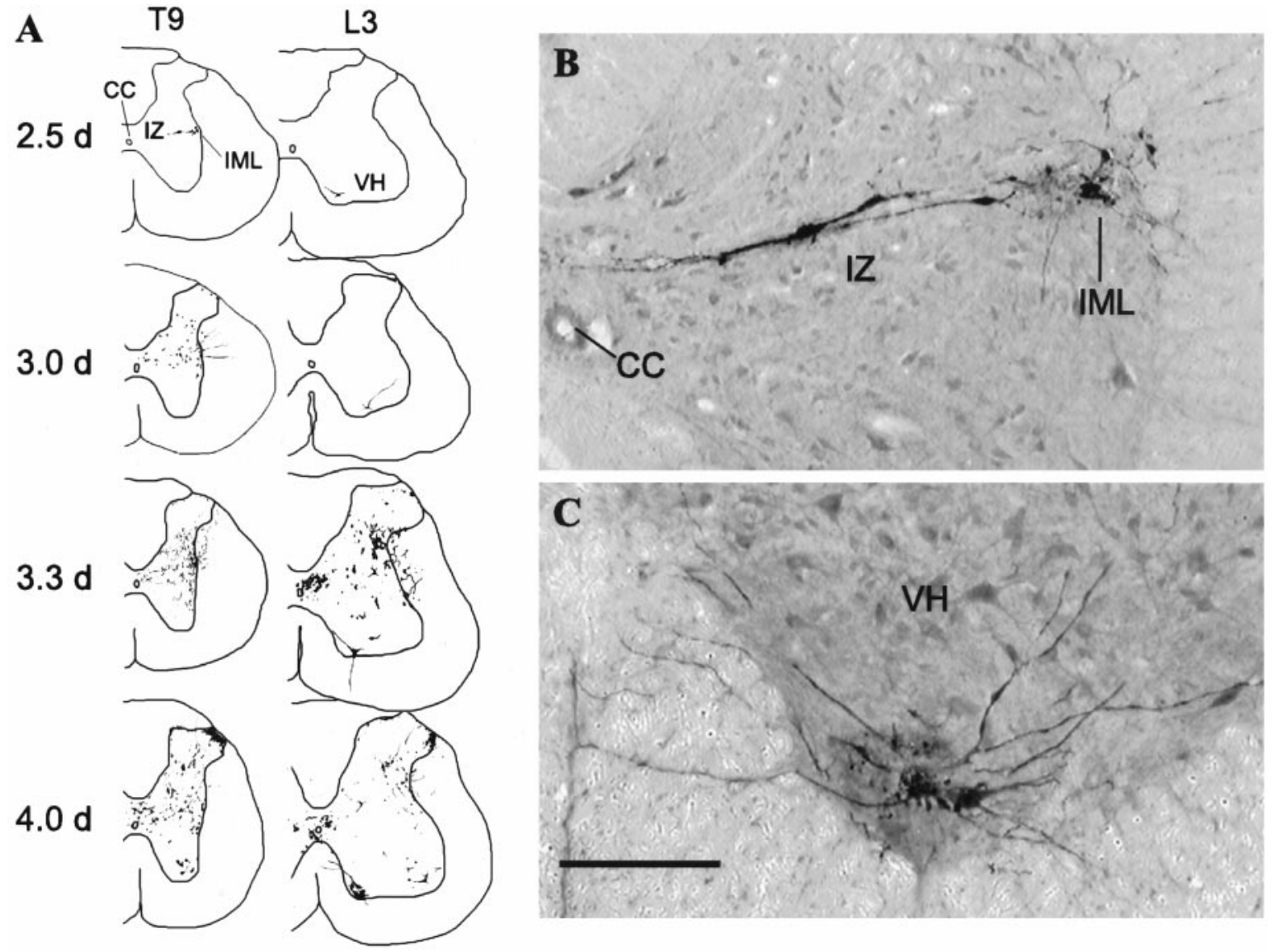

Figure 1. PRV immunoreactivity in the spinal cord after injection into the lordosis-producing muscles. $A$, Representative drawings of the morphology and distribution of PRV-immunoreactive neurons in the thoracic and lumbar spinal cord 2.5, 3.0, 3.3, and $4.0 \mathrm{~d}$ after PRV injection. At each time point, drawings are from the same animal. $B, C$, Representative PRV-immunoreactive neurons in the intermediate gray and IML $(B)$ and the ventral horn $(C)$ in sections taken from spinal segments T9 and L2, respectively, $2.5 \mathrm{~d}$ after PRV injection into the lordosis-producing muscles. Scale bar, $200 \mu \mathrm{m}$. $C C$, Central canal; $I Z$, intermediate zone; $V H$, ventral horn.

of the PRV-labeled neurons revealed new details about this circuit.

\section{MATERIALS AND METHODS}

Animals. Male $(n=10)$ and female $(n=12)$ adult Sprague Dawley rats (Charles River Laboratories, Wilmington, MA) weighing between 210 and $305 \mathrm{gm}$ were used in these experiments. Animals were housed in plastic shoebox cages in same-sex pairs in a temperature-controlled room $\left(22^{\circ} \mathrm{C}\right)$ with a $12 \mathrm{hr}$ light/dark cycle. Rat chow (Ralston Purina, St. Louis, MO) and tap water were available ad libitum. All animals were allowed at least 1 week to acclimate to the colony before any experimental procedures began. The handling and care of experimental animals conformed to the regulations provided by the NIH Guide for the Care and Use of Laboratory Animals, and the experimental protocols for the use of virus were approved by the Institutional Animal Care and Use Committee.

Tracer Injections. PRV was prepared as described previously (Card et al., 1990). All work with the active virus was conducted in a Biosafety Level 2 containment facility. Infected animals were not removed from this facility until the virus had been inactivated by perfusion with fixative, as described below. An attenuated strain of PRV, Bartha, was used in all of the present experiments because of its reduced virulence, which permits longer survival times (Card et al., 1992). Two stocks of PRV were used with titers of $2.0 \times 10^{7}$ and $6.75 \times 10^{8} \mathrm{pfu} / \mathrm{ml}$.

Surgeries were performed during anesthesia with ketamine and xylazine ( 90 and $12 \mathrm{mg} / \mathrm{ml}$, respectively) using aseptic procedures. A midline longitudinal incision, $\sim 5 \mathrm{~cm}$, was made in the dorsal lumbar region. The skin and aponeurosis were reflected laterally, and the L5 vertebra was located using the depression between the lumbar and sacral vertebra as a landmark. Three unilateral $1 \mu$ injections were made with a Hamilton
(Reno, NV) syringe at the level of the L5 vertebra at the following approximate distances from midline: 3,8 , and $12 \mathrm{~mm}$. Injection sites were chosen to correspond to the transversospinalis, medial longissimus, and lateral longissimus muscles, respectively (Cottingham et al., 1987). All injections were made perpendicular to the muscle surface and were $\sim 1.5$ $\mathrm{mm}$ deep. After each of the three injections, the muscle surface was rinsed with saline and dried. Animals were allowed to survive for $2.0 \mathrm{~d}$ (female, $n=1$ ), $2.5 \mathrm{~d}$ (female, $n=3$; male, $n=2$ ), $3.0 \mathrm{~d}$ (female, $n=2$; male, $n=2$ ), $3.3 \mathrm{~d}$ (female, $n=2$; male, $n=2$ ), or $4.0 \mathrm{~d}$ (female, $n=4$; male, $n=4)$.

Animals were killed during deep anesthesia by transcardial perfusion with $100 \mathrm{ml}$ of $0.9 \% \mathrm{NaCl}$ containing $0.1 \%$ heparin followed by $400-500$ $\mathrm{ml}$ of $4 \%$ paraformaldehyde in $0.1 \mathrm{~m}$ phosphate buffer (PB), $\mathrm{pH}$ 7.4-7.6. Brains and spinal cords were removed from the crania and vertebral columns, respectively. After $24 \mathrm{hr}$ of post-fixation at $4^{\circ} \mathrm{C}$, the brains were submerged in $20 \%$ sucrose in $0.1 \mathrm{M} \mathrm{PB}, \mathrm{pH} 7.4$, for at least $24 \mathrm{hr}$ at $4^{\circ} \mathrm{C}$. The spinal cords were dissected to expose the dorsal rootlets. Transections were made between $\mathrm{C} 8$ and $\mathrm{T} 1$, between $\mathrm{T} 7$ and $\mathrm{T} 8$, and between each segment from T8 to L5 using approximately half the distance between dorsal roots of adjacent segments as the boundary for each segment. After these transections, individual segments were submerged in $20 \%$ sucrose in $0.1 \mathrm{M} \mathrm{PB}$ for at least $24 \mathrm{hr}$. Brains and spinal cords were frozen and cut on a freezing microtome. Brains were cut coronally into either 30 or $40 \mu \mathrm{m}$ sections and distributed serially into four or three sets, respectively. Spinal cords were cut in $40 \mu \mathrm{m}$ horizontal (C1-C8 and T1-T7 samples) or coronal (T8-L5) sections and distributed serially into two wells. In some cases horizontal, rather than coronal, sections were taken through the lumbar and lower thoracic spinal cord. All sections were initially placed into Tris-buffered saline (TBS), $\mathrm{pH} 7.4$, and then transferred to cryoprotectant (Watson et al., 1986) for storage at $-20^{\circ} \mathrm{C}$. 
Table 1. Counts of cell profiles in the spinal cord of rats $2.5,3$, and 3.3 d after injection of PRV into the lordosis-producing muscles

\begin{tabular}{llll} 
Area & $\begin{array}{l}\text { No. of ani- } \\
\text { mals with } \\
\text { label }\end{array}$ & $\begin{array}{l}\text { Cells per } \\
\text { labeled section } \\
\text { (mean) }\end{array}$ & $\begin{array}{l}\text { No. of labeled } \\
\text { sections per } \\
\text { animal (range) }\end{array}$ \\
\hline
\end{tabular}

$2.5 \mathrm{~d}(n=5)$

Ventral horn

$\begin{array}{llll}\text { Lateral } & 1 / 5 & 1.0 & 0-1 \\ \text { Central } & 0 / 5 & 0.0 & 0 \\ \text { Medial } & 4 / 5 & 1.1 & 0-4 \\ \text { Area X } & 5 / 5 & 1.2 & 3-11 \\ \text { ntermediate zone } & & & 8-18 \\ \begin{array}{l}\text { Ipsilateral } \\ \text { Contralateral }\end{array} & 5 / 5 & 1.8 & 0 \\ \text { ML } & 0 / 5 & 0.0 & \\ \text { Ipsilateral } & 5 / 5 & 2.2 & 0 \\ \text { Contralateral } & 0 / 5 & 0.0 & \\ \text { Dorsal horn } & & & 0 \\ \text { Ipsilateral } & 0 / 5 & 0.0 & 0 \\ \text { Contralateral } & 0 / 5 & 0.0 & \end{array}$

$3 \mathrm{~d}(n=2)$

Ventral horn

Lateral

Central

Medial

Area X

Intermediate zone

Ipsilateral $\quad 2 / 2$

Contralateral $2 / 2$

IML

$\begin{array}{ll}\text { Ipsilateral } & 2 / 2 \\ \text { Contralateral } & 2 / 2\end{array}$

Dorsal horn

Ipsilateral

Contralateral

$$
2 / 2
$$

$2 / 2$

1.3
1.3
1.0
4.4

1.3

1.3

25-36

1.0

$19-21$

$8-13$

4.4

$180-217$

$3.3 \mathrm{~d}(n=2)$

Ventral horn

$\begin{array}{lccc}\text { Lateral } & 2 / 2 & 2.2 & 114-144 \\ \text { Central } & 2 / 2 & 1.8 & 86-133 \\ \text { Medial } & 2 / 2 & 1.7 & 46-80\end{array}$

The numbers of animals with label are presented as the number of animals with labeled cells in a given area per total number of animals investigated at a given time point.

Immunocytochemistry. Free-floating sections were removed from the cryoprotectant and washed with TBS. All washes and incubations occurred at room temperature. The sections then were incubated in $0.03 \%$ $\mathrm{H}_{2} \mathrm{O}_{2}$ (Fisher Scientific, Houston, TX) and 0.25\% Triton X-100 (LabChem, Inc., Pittsburgh, PA) in TBS for $15 \mathrm{~min}$. Sections then were transferred to tubes containing primary antisera, either goat anti-PRV (GB320, 1:10,000) or rabbit anti-PRV (RB133, 1:7500), diluted in 3\% normal donkey or goat serum, respectively, and $0.25 \%$ Triton X-100 in TBS for 35-45 hr. Sections then were washed with TBS and incubated in secondary antisera for $2 \mathrm{hr}$, using either donkey anti-goat (1:1000; Jackson ImmunoResearch, West Grove, PA) or goat anti-rabbit (1:250; Vector Laboratories, Burlingame, CA). Both secondary antibodies were diluted in $3 \%$ normal serum corresponding to the host species of the secondary antibody and $0.25 \%$ Triton X-100 in TBS. After washing with TBS, sections were incubated in an avidin-biotin-peroxidase complex (Vector Elite kit; 1:222 in 0.25\% Triton X-100 in TBS) for $1 \mathrm{hr}$. Sections then were washed with TBS, followed by a single wash with $50 \mathrm{~mm}$ Tris. PRV immunoreactivity was visualized by reacting the sections with $3,3^{\prime}$-diaminobenzidine $(0.2 \mathrm{mg} / \mathrm{ml})$, nickel sulfate $(25 \mathrm{mg} / \mathrm{ml})$, and $0.025 \% \mathrm{H}_{2} \mathrm{O}_{2}$ in $50 \mathrm{~mm}$ Tris for $5-10 \mathrm{~min}$. The reaction was terminated with TBS washes. Sections were mounted on gelatinized slides, counter- stained with methyl green, dehydrated with increasing concentrations of alcohol followed by Hemo-De (Fisher Scientific), and then coverslipped with Permount (Fisher Scientific).

Data analysis. Sections were analyzed by light microscopy using an Olympus Optical (Tokyo, Japan) BH50 microscope, and anatomical boundaries were defined according to Paxinos and Watson (1986). PRVimmunoreactive cells were dark blue to black and had a Golgi-like appearance. Digital images were obtained using a Sony (Tokyo, Japan) DKC digital camera, imported into Adobe Systems (San Jose, CA) PhotoShop 4.0, and printed with an Eastman Kodak (Rochester, NY) 8650PS dye sublimation printer. Atlas-like illustrations of labeling were created by superimposing the digital photomicrographs on the digital representations of Paxinos and Watson (1986) using Adobe PhotoShop version 4.0. Dots were used to represent the precise location of labeled cells on the atlas images, and then the micrograph was eliminated from the image. All other drawings were created by importing a digital micrograph into PhotoShop and using the paintbrush tool in a camera lucida-like manner to draw the images.

A morphological analysis of the PRV-immunoreactive neurons in the PAG after $4 \mathrm{~d}$ of infection was conducted. Anatomical subdivisions and classification of cell types were primarily based on the methods of Beitz (1985) and Beitz and Shepard (1985), respectively. However, because neuronal processes were not always visible in our preparations, we relied on soma shape as the primary indicator of cell type. Cell profiles in our preparations were designated as fusiform (elongated), spheroid (nearly circular), or triangular (triangular or teardrop), which corresponded, respectively, to the bipolar, multipolar, and triangular profiles of Beitz and Shepard (1985). Each cell type was exhibited by both large and small neurons, as previously reported, but such size distinctions were not examined here.

Statistical analysis. Tests for statistically significant differences were conducted using SigmaStat (version 1.0; Jandel Scientific, Corte Madera, CA) or JMP IN (version 3.1.5; SAS Institute, Cary, NC). Bonferonni corrected $p$ values were used to test for significant correlations and were calculated by dividing 0.05 by the number of comparisons for a given test. Comparisons were made using a one-way ANOVA or Friedman's repeated measures ANOVA, and interactions were tested using a two-way repeated measures ANOVA. Significant differences were further analyzed using Student-Newman-Keuls post hoc tests with $\alpha=0.05$. When $n \geq 3$ data are presented as the mean \pm SEM unless otherwise indicated.

\section{RESULTS}

Lumbar epaxial muscle injection of PRV resulted in a consistent pattern of neuronal labeling in the spinal cord and brain. At progressively longer survival intervals, additional populations of cells were labeled sequentially, suggesting a hierarchical series of neuronal connections. The time course of PRV neuronal tract tracing is presented within each level of the CNS. Although the tables and figures provide a comprehensive description of the affected brain regions, the text will focus on areas previously implicated in facilitating the lordosis reflex.

\section{Spinal cord}

The shortest survival time examined was $2.0 \mathrm{~d}$ ( $n=1$ female). At this time PRV immunoreactivity was extremely limited. In particular, there were no PRV-immunoreactive neurons detected in the lumbar spinal cord. There was, however, one PRV-labeled cell per section detected in the intermediolateral cell column (IML) in three sections taken from the T11 level. Based on the low level of viral transmission at this time, later time points were chosen for further study.

Figure $1 A$ illustrates the distribution of PRV-labeled neurons in the spinal cord 2.5, 3.0, 3.3, and $4.0 \mathrm{~d}$ after PRV injection into the lumbar epaxial muscles. Quantification of the labeled spinal neurons is presented in Table 1 . At $2.5 \mathrm{~d}$ after injection, there was prominent labeling in the IML (Fig. $1 B$ ) in sections from spinal segments T8-L2 in all animals examined $(n=5)$. PRVimmunoreactive cells also were detected in the area surrounding the central canal (area X, spinal segments T10-L2) and in the 
Table 2. Localization of PRV immunoreactivity in the brain after PRV injection into the lordosis-producing muscles

\begin{tabular}{lllll} 
& & \multicolumn{3}{c}{ Survival time $(\mathrm{d})$} \\
\cline { 2 - 4 } Area & 3.0 & 3.3 & 4.0
\end{tabular}

Medulla

Area postrema

$\mathrm{C} 1$ cell group

Caudoventrolateral reticular nucleus

Dorsal paragigantocellular nucleus

Gigantocellular nucleus

$\alpha$

Proper

Ventral

Medullary reticular field

Dorsal

Ventral

Intermediate reticular nucleus

Nucleus of the solitary tract

Nucleus retroambiguus

Raphe

Magnus

Obscurus

Pallidus

Rostral ventrolateral medulla

Vestibular nucleus

Lateral

Medial

Superior

Pons and midbrain

A5 cell group

Deep mesencephalic reticular nucleus

Dorsal longitudinal fasciculus

Dorsal raphe nucleus

Edinger-Westphal nucleus

Interstitial nucleus medial longitudinal fasciculus

Laterodorsal tegmental nucleus

Locus coeruleus

Parabrachial nucleus

Pedunculopontine tegmental nucleus

Periaqueductal gray

Peritrigeminal zone

Pontine reticular nucleus

Caudal

Oral

Ventral

Precommissural nucleus

Prerubral field

Red nucleus

Retrorubral field

Subcoeruleus nucleus

$\alpha$

Dorsal

Ventral

Substantia nigra

Forebrain

Anterior hypothalamus

Anterior medial preoptic area

Arcuate nucleus

\begin{tabular}{|c|c|c|}
\hline $0 / 4$ & $0 / 4$ & $7 / 7$ \\
\hline $0 / 4$ & $0 / 4$ & $5 / 7$ \\
\hline $0 / 4$ & $0 / 4$ & $6 / 7$ \\
\hline $0 / 4$ & $3 / 4$ & $7 / 7$ \\
\hline $2 / 4$ & $4 / 4$ & $7 / 7$ \\
\hline $0 / 4$ & $4 / 4$ & $7 / 7$ \\
\hline $2 / 4$ & $4 / 4$ & $7 / 7$ \\
\hline $0 / 4$ & $0 / 4$ & $7 / 7$ \\
\hline $0 / 4$ & $3 / 4$ & $7 / 7$ \\
\hline $0 / 4$ & $4 / 4$ & $7 / 7$ \\
\hline $0 / 4$ & $3 / 4$ & $7 / 7$ \\
\hline $0 / 4$ & $3 / 4$ & $7 / 7$ \\
\hline $0 / 4$ & $3 / 4$ & $7 / 7$ \\
\hline $2 / 4$ & $4 / 4$ & $7 / 7$ \\
\hline $2 / 4$ & $4 / 4$ & $7 / 7$ \\
\hline $4 / 4$ & $4 / 4$ & $7 / 7$ \\
\hline $0 / 4$ & $0 / 4$ & $5 / 7$ \\
\hline $0 / 4$ & $3 / 4$ & $7 / 7$ \\
\hline $0 / 4$ & $0 / 4$ & $6 / 7$ \\
\hline $4 / 4$ & $4 / 4$ & $7 / 7$ \\
\hline $0 / 4$ & $0 / 4$ & $6 / 7$ \\
\hline $0 / 4$ & $2 / 4$ & $7 / 7$ \\
\hline $0 / 4$ & $0 / 4$ & $7 / 7$ \\
\hline $0 / 4$ & $2 / 4$ & $7 / 7$ \\
\hline $0 / 4$ & $0 / 4$ & $7 / 7$ \\
\hline $0 / 4$ & $0 / 4$ & $7 / 7$ \\
\hline $2 / 4$ & $4 / 4$ & $7 / 7$ \\
\hline $0 / 4$ & $0 / 4$ & $6 / 7$ \\
\hline $0 / 4$ & $0 / 4$ & $7 / 7$ \\
\hline $0 / 4$ & $4 / 4$ & $7 / 7$ \\
\hline $0 / 4$ & $0 / 4$ & $5 / 7$ \\
\hline $0 / 4$ & $3 / 4$ & $7 / 7$ \\
\hline $0 / 4$ & $2 / 4$ & $6 / 7$ \\
\hline $0 / 4$ & $2 / 4$ & $7 / 7$ \\
\hline $0 / 4$ & $0 / 4$ & $7 / 7$ \\
\hline $0 / 4$ & $2 / 4$ & $5 / 7$ \\
\hline $0 / 4$ & $0 / 4$ & $7 / 7$ \\
\hline $0 / 4$ & $0 / 4$ & $6 / 7$ \\
\hline $0 / 4$ & $4 / 4$ & $7 / 7$ \\
\hline $2 / 4$ & $3 / 4$ & $7 / 7$ \\
\hline $0 / 4$ & $4 / 4$ & $7 / 7$ \\
\hline $0 / 4$ & $2 / 4$ & $7 / 7$ \\
\hline $0 / 4$ & $0 / 4$ & $5 / 7$ \\
\hline $0 / 4$ & $0 / 4$ & $6 / 7$ \\
\hline $0 / 4$ & $0 / 4$ & $7 / 7$ \\
\hline
\end{tabular}

Table 2. Continued

\begin{tabular}{|c|c|c|c|}
\hline \multirow[b]{2}{*}{ Area } & \multicolumn{3}{|c|}{ Survival time $(\mathrm{d})$} \\
\hline & 3.0 & 3.3 & 4.0 \\
\hline \multicolumn{4}{|l|}{ Bed nucleus of the stria terminalis } \\
\hline Anterior medial & $0 / 4$ & $0 / 4$ & $5 / 7$ \\
\hline Lateral ventral & $0 / 4$ & $0 / 4$ & $6 / 7$ \\
\hline Medial posterolateral & $0 / 4$ & $0 / 4$ & $5 / 7$ \\
\hline Ventral & $0 / 4$ & $0 / 4$ & $7 / 7$ \\
\hline Dorsal cortex & $2 / 4$ & $4 / 4$ & $7 / 7$ \\
\hline Dorsal hypothalamic area & $0 / 4$ & $3 / 4$ & $7 / 7$ \\
\hline Dorsomedial hypothalamic nucleus & $0 / 4$ & $0 / 4$ & $6 / 7$ \\
\hline Lateral hypothalamus & $0 / 4$ & $3 / 4$ & $7 / 7$ \\
\hline \multicolumn{4}{|l|}{ Preoptic area } \\
\hline Lateral & $0 / 4$ & $0 / 4$ & $7 / 7$ \\
\hline Medial & $0 / 4$ & $0 / 4$ & $7 / 7$ \\
\hline Medial preoptic nucleus & $0 / 4$ & $0 / 4$ & $6 / 7$ \\
\hline \multicolumn{4}{|l|}{ Organum vasculosum of the lamina } \\
\hline terminalis & $0 / 4$ & $0 / 4$ & $6 / 7$ \\
\hline \multicolumn{4}{|l|}{ Paraventricular hypothalamic nucleus } \\
\hline Dorsal cap & $4 / 4$ & $4 / 4$ & $7 / 7$ \\
\hline Medial parvocellular & $0 / 4$ & $4 / 4$ & $7 / 7$ \\
\hline Ventral & $0 / 4$ & $4 / 4$ & $7 / 7$ \\
\hline Perifornical area & $0 / 4$ & $0 / 4$ & $6 / 7$ \\
\hline Periventricular hypothalamus & $0 / 4$ & $2 / 4$ & $7 / 7$ \\
\hline Posterior hypothalamus & $0 / 4$ & $0 / 4$ & $5 / 7$ \\
\hline Posterior retrochiasmatic area & $0 / 4$ & $3 / 4$ & $7 / 7$ \\
\hline Retrochiasmatic area & $0 / 4$ & $4 / 4$ & $7 / 7$ \\
\hline Reuniens thalamic nucleus & $0 / 4$ & $0 / 4$ & $4 / 7$ \\
\hline Subfornical organ & $0 / 4$ & $0 / 4$ & $6 / 7$ \\
\hline Suprachiasmatic nucleus & $0 / 4$ & $0 / 4$ & $5 / 7$ \\
\hline \multicolumn{4}{|l|}{ Ventromedial hypothalamic nucleus } \\
\hline Central & $0 / 4$ & $0 / 4$ & $5 / 7$ \\
\hline Dorsomedial & $0 / 4$ & $0 / 4$ & $4 / 7$ \\
\hline Rostral & $0 / 4$ & $0 / 4$ & $6 / 7$ \\
\hline Ventrolateral & $0 / 4$ & $0 / 4$ & $7 / 7$ \\
\hline Zona incerta & $0 / 4$ & $0 / 4$ & $4 / 7$ \\
\hline
\end{tabular}

The numbers provided represent the number of animals that had labeling in a given area out of the total number of animals investigated for each time point.

intermediate zone, defined here as the ventral portion of lamina $\mathrm{V}$ and the dorsal portion of lamina VII, including the intermediomedial nucleus (T9-L2). In addition, PRV-immunoreactive neurons were detected in lamina IX of the medial (Fig. 1C) and lateral ventral horn in spinal segments L2-L4 and L3, respectively. The location and morphology of these ventral horn neurons is consistent with that of motoneurons (Molander et al., 1984) and is consistent with the location of lumbar epaxial muscle-projecting neurons in the spinal cord (Brink et al., 1979).

For animals killed $3.0 \mathrm{~d}$ after PRV injection, spinal cord tissue was obtained in both the horizontal $(n=2)$ and coronal $(n=2)$ planes. In all cases, labeled cells were observed both ipsilateral and contralateral to the PRV injection in IML in spinal segments T8-L2 and in the dorsal horn, area X, and the intermediate zone in spinal segments T8-L5. In addition, labeled cells were found in the lateral, central, and medial portions of the ipsilateral ventral horn.

Spinal cords were analyzed in two of the four animals (one female and one male) killed $3.3 \mathrm{~d}$ after PRV injection and two of the seven animals (one female and one male) killed $4 \mathrm{~d}$ after PRV injection. At these times there was extensive labeling in all ani- 


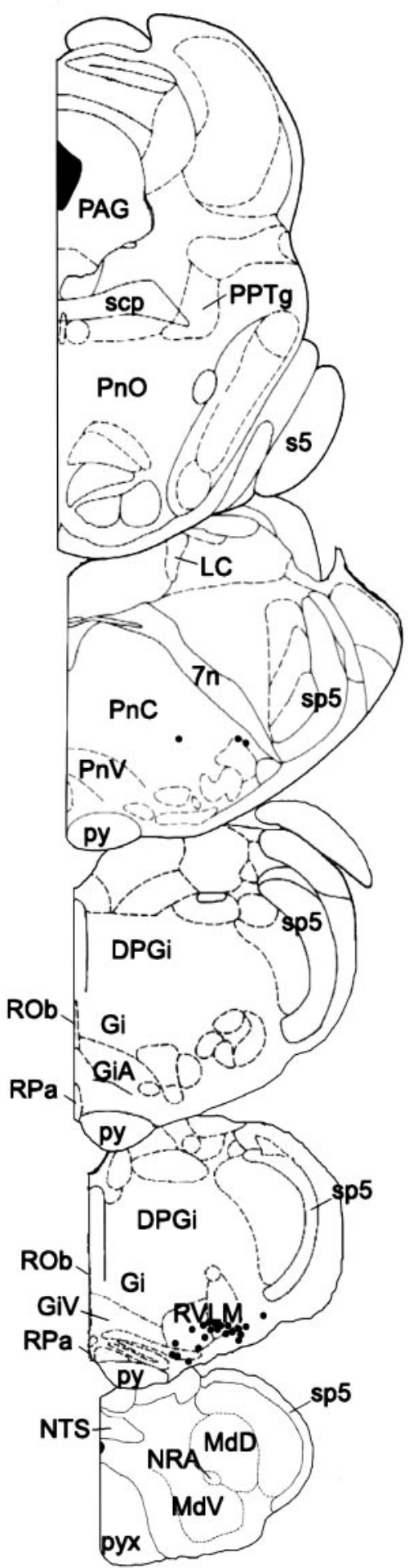

3.0 days

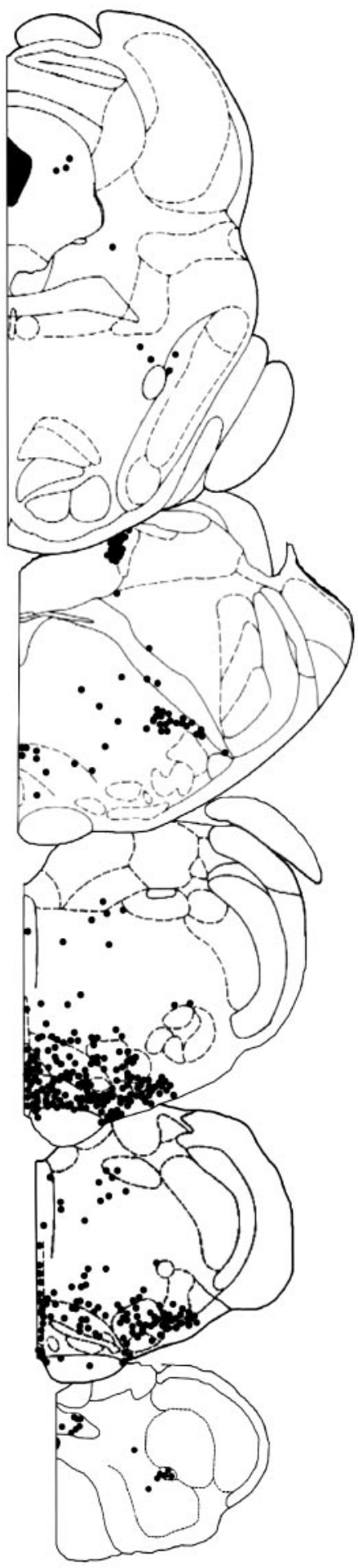

3.3 days

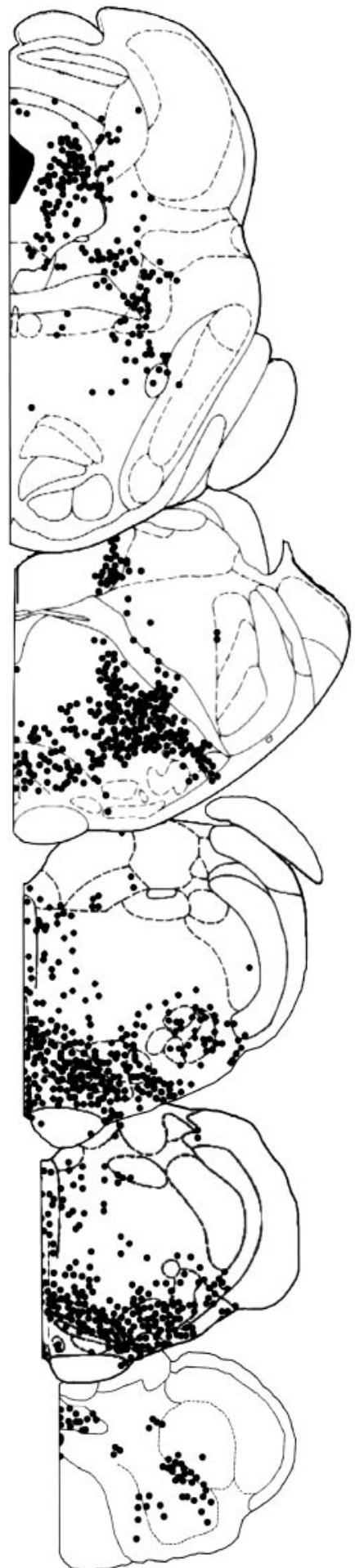

4.0 days

Figure 2. Plots of the distribution of PRV-immunoreactive neurons in the medulla, pons, and midbrain of representative female rats 3.0, 3.3, and 4.0 d after PRV injection into the lordosis producing muscles. Each dot represents one or two cells, and drawings are arranged with the most rostral section on top. Drawings are modified from Paxinos and Watson (1986). 7n, Facial nerve; DPGi, dorsal paragigantocellular nucleus; Gi, gigantocellular nucleus; $G i A, \alpha$ division of the gigantocellular nucleus; $G i V$, ventral gigantocellular nucleus; $L C$, locus coeruleus; $M d D$, dorsal medullary reticular field; $M d V$, ventral medullary reticular field; $N R A$, nucleus retroambiguus; $N T S$, nucleus of the solitary tract; $P n C$, caudal pontine reticular nucleus; $P n O$, oral pontine reticular nucleus; PnV, ventral pontine reticular nucleus; PPTg, pedunculopontine tegmental nucleus; py, pyramidal tract; pyx, pyramidal decussation; $R O b$, raphe obscurus; $R P a$, raphe pallidus; $R V L M$, rostral ventrolateral medulla; $s 5$, sensory root of the trigeminal nerve; scp, superior cerebellar peduncle; $s p 5$, spinal trigeminal tract. 


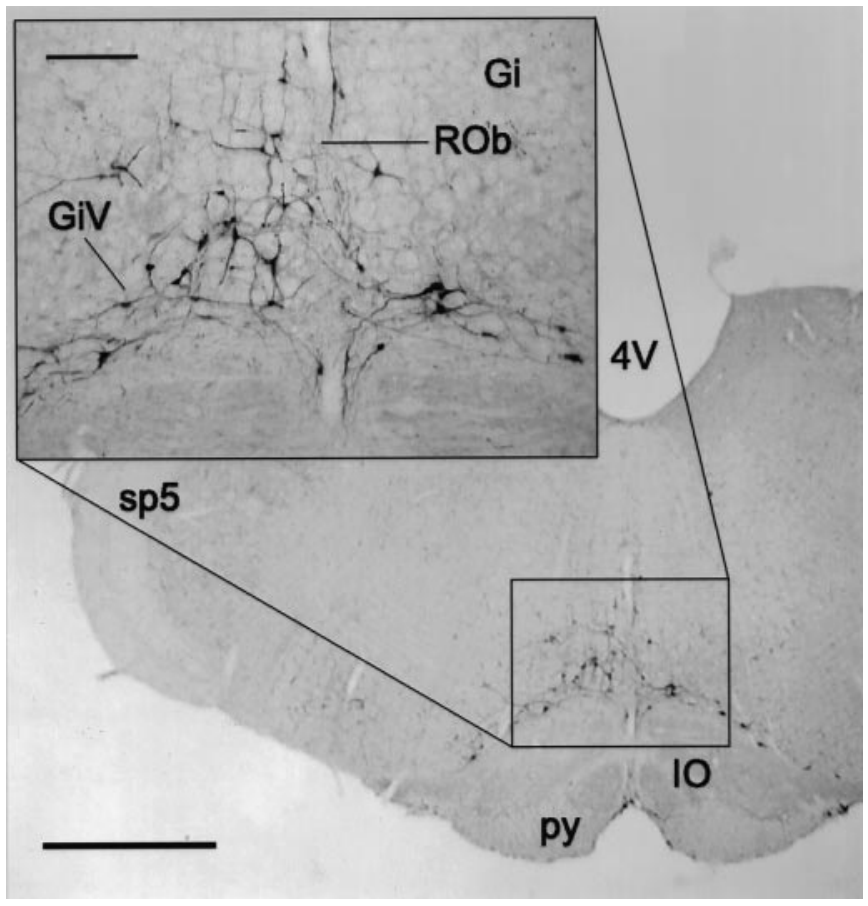

Figure 3. Representative micrograph of PRV-immunoreactive neurons in the MRF 3.3 d after PRV injection into the lordosis-producing muscles. Inset, Higher magnification of the indicated area. Scale bars: $1 \mathrm{~mm}$; inset, $200 \mu \mathrm{m}$. $4 V$, Fourth ventricle; $G i$, gigantocellular nucleus; GiV, ventral gigantocellular nucleus; $I O$, inferior olive; $p y$, pyramidal tract; $R O b$, raphe obscurus; sp5, spinal trigeminal tract.

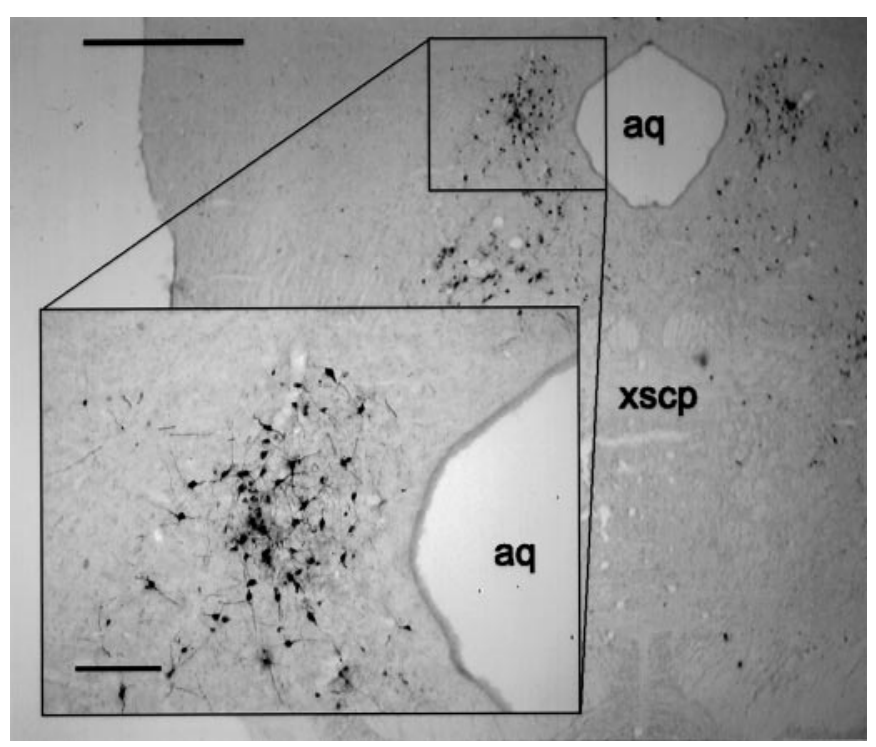

Figure 4. Representative micrograph of PRV-immunoreactive neurons in the PAG $4.0 \mathrm{~d}$ after PRV injection into the lordosis-producing muscles. The section shown is approximately $-8.00 \mathrm{~mm}$ relative to bregma according to Paxinos and Watson (1986). Inset, Higher magnification of the indicated area. Scale bars: $1 \mathrm{~mm}$; inset, $200 \mu \mathrm{m}$. aq, Aqueduct; $x s c p$, decussation of the superior cerebellar peduncle.

mals in the IML, area $\mathrm{X}$, intermediate gray, and dorsal horn, preventing accurate quantification of the labeled cells per section. An analysis of the neurons in the ventral horn for animals killed $3.3 \mathrm{~d}$ after PRV injection revealed a similar pattern of labeling as seen $3 \mathrm{~d}$ after injection (Table 1).

\section{Medulla}

Table 2 summarizes the arrival of PRV in various regions of the brain, and Figure 2 illustrates the time course of labeling in the hindbrain. The earliest postinjection time that PRV was observed in the medulla was $3.0 \mathrm{~d}$. At this time, labeled cells were detected in the rostral ventrolateral medulla, including the lateral paragigantocellular nucleus in all animals. Labeled cells also were observed in two of four animals in the $\alpha$ and ventral gigantocellular nucleus and the raphe obscurus and pallidus. At $3.3 \mathrm{~d}$, all animals had detectable labeling in the areas identified at $3.0 \mathrm{~d}$, including the gigantocellular nucleus and its subdivisions (Fig. 3). After $4.0 \mathrm{~d}$ of survival, all previously labeled areas were PRV-immunoreactive.

\section{Pons and midbrain}

The earliest postinjection time that revealed PRV-labeled neurons in the pons or midbrain was $3.0 \mathrm{~d}$. However, the only region consistently labeled was the area around the A5 cell group. At the $3.3 \mathrm{~d}$ survival time, additional labeling appeared in the PAG (four of four animals); however, there were only a few PRVimmunoreactive PAG neurons found in each animal. After $4.0 \mathrm{~d}$ of survival, many more neurons were labeled in the PAG. Figure 4 illustrates representative immunostaining in the PAG $4.0 \mathrm{~d}$ after injection of PRV into the lordosis-producing muscles. Although 30 or $40 \mu \mathrm{m}$ sections were cut from these animals, a comparison of the cell counts taken from sections with different thickness revealed that they were not significantly different (one-way ANOVA, $F=0.075 ; p=0.8037)$. Thus, the cell counts from these animals are presented together in the analysis below.

A statistical analysis was conducted on the localization of PRV-immunoreactive neurons in the longitudinal columns of the PAG $4.0 \mathrm{~d}$ after injection of PRV into the lordosis-producing muscles (Fig. 5). One male animal was not included, because the PRV-immunoreactive cells were too numerous to obtain accurate cell counts. A two-way ANOVA (rostrocaudal poles vs longitudinal columns) showed a significant effect of the number of labeled neurons found in the longitudinal columns of the PAG $(F=9.78$; $p=0.0008)$, the rostral versus caudal poles of the PAG $(F=$ $15.29 ; p=0.0113)$, and an interaction between subdivision and rostral-caudal localization $(F=15.07 ; p<0.0001$; Fig. $5 B)$. Post $h o c$ analysis showed that the number of labeled neurons was greater in the caudal than the rostral PAG and greater in the ventrolateral PAG than all other longitudinal columns.

The PRV-immunoreactive neurons in the PAG were analyzed further according to their morphology and were categorized as either fusiform, spheroid, or triangular (Fig. 5C), which correspond to the bipolar, multipolar, and triangular morphologies defined by Beitz and Shepard (1985), respectively. Based on a minimum of 12 sections per animal, counts of cell profiles showed that the fusiform, spheroid, and triangular cell morphologies comprised an average of $25.5,56.2$, and $15.5 \%$ of the total PRV-labeled cells in the PAG, respectively. An average of $2.8 \%$ of the PRV-labeled cells in the PAG were not identifiable because of disrupted membranes commonly seen in long-term PRV infections. Statistical analysis of the distribution of these cell morphologies across the longitudinal columns of the PAG confirmed that the subdivisions did not differ in the proportions of these cell types (Fig. 5D).

Although many of the PRV-labeled areas have been previously associated with autonomic control, including the MRF and the PAG, PRV also was detected in some areas involved in motor 
A

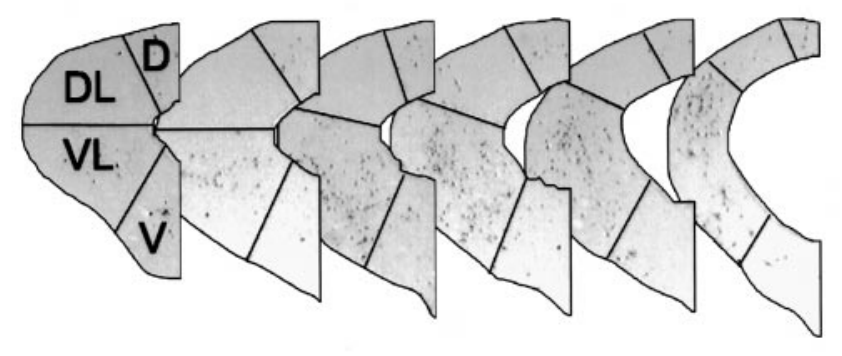

B

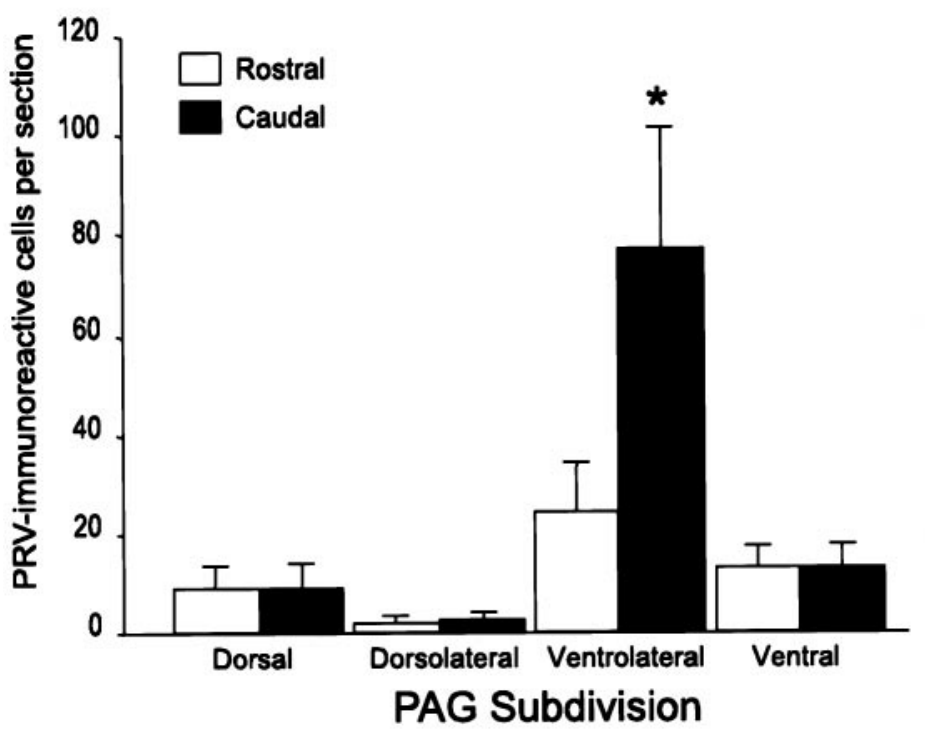

C

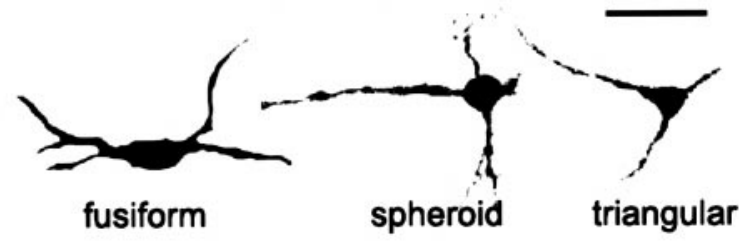

D

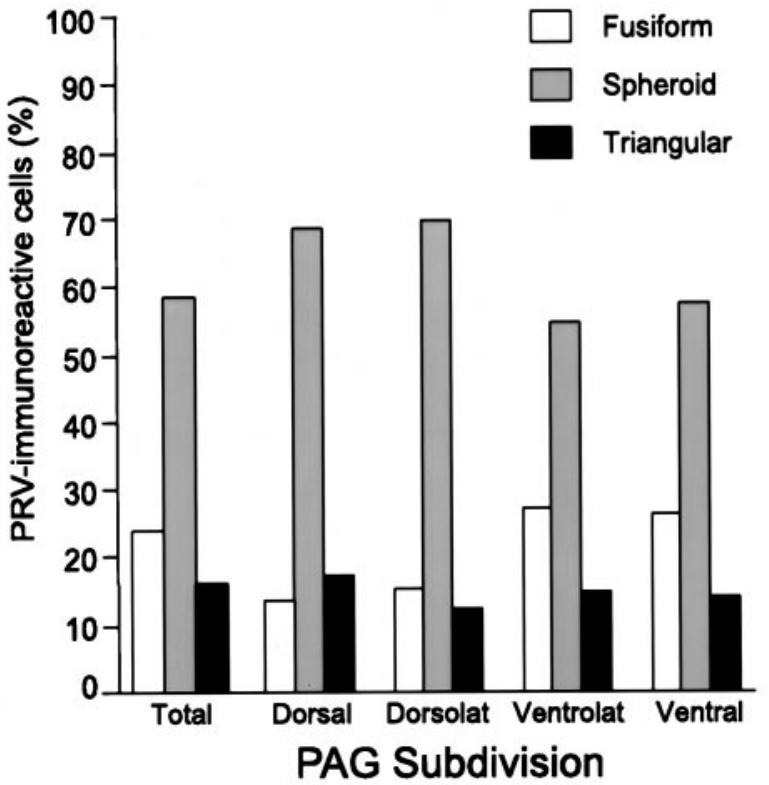

Figure 5. Distribution and morphology of PRV-immunoreactive neurons in the PAG $4.0 \mathrm{~d}$ after PRV injection into the lumbar epaxial muscles. $A$, Subdivisions of the PAG used for this analysis, with the most rostral section to the left. $B$, Number of PRV-positive neurons per section in the subdivisions of the rostral and caudal PAG (mean $\pm \mathrm{SEM} ;{ }^{*} p<0.05$ ). $C$, Representative PRV-immunoreactive neurons in the PAG illustrating, from left to right, the fusiform, spheroid, and triangular cell profiles found in the PAG. Scale bar, $50 \mu \mathrm{m}$. D, Distribution of these cell types in the subdivisions of the PAG. For all analysis of the PAG, $n=6$.

control. For instance, the red nucleus was labeled in seven of seven animals $4 \mathrm{~d}$ after the PRV injections (Fig. 6A).

\section{Forebrain}

Plots of the time course of labeling in the forebrain are shown in Figure 7, and labeled areas are summarized in Table 2. Labeling in the forebrain was first detected $3.0 \mathrm{~d}$ after injection of PRV into the lordosis-producing muscles; however, the only area consistently labeled (four of four animals) was the dorsal cap of the paraventricular nucleus of the hypothalamus. Occasionally, labeled cells were observed at this time point in the motor area of the dorsal cortex and the dorsal hypothalamic area (two of four animals). Labeled cells were consistently observed in these areas in animals allowed to survive for $4.0 \mathrm{~d}$. Figure $6 \mathrm{~B}$ shows a representative micrograph of the labeling observed in the motor area of the dorsal cortex. The cortical labeling was localized between the areas identified as the hindlimb and forelimb areas of the cortex according to Paxinos and Watson (1986). It was not until the $4.0 \mathrm{~d}$ survival time that PRV was apparent in the arcuate nucleus (seven of seven animals), ventrolateral VMN (vl-VMN, seven of seven animals), rostral VMN (six of seven animals), central VMN (five of seven animals), and dorsomedial VMN (four of seven animals). Figure $8 A$ shows an example of repre- sentative staining in the caudal vl-VMN $4.0 \mathrm{~d}$ after injection of PRV into the lordosis-producing muscles. An analysis of the number of PRV-labeled neurons in the VMN showed a significantly greater number in the vl-VMN compared with the other VMN subdivisions (Fig. 8B; Friedman's repeated measures ANOVA, $\chi^{2}=11.4 ; p=0.0099$, Student-Newman-Keuls post hoc analysis).

Tests for significant correlations between the average number of PRV-labeled neurons per section in the rostral, central, dorsomedial, and vl-VMN and the average number of PRV-labeled neurons per section in the dorsal, dorsolateral, ventrolateral, and ventral PAG were conducted. Using Bonferonni-corrected $p$ values, we found a significant correlation between the average number of cell profiles per section in the vl-VMN and the dorsal $(r=$ $0.999 ; p<0.0001)$, the ventrolateral $(r=0.971 ; p=0.00121)$, and the ventral PAG $(r=0.967 ; p=0.00165)$. A significant correlation also existed between the rostral $\mathrm{VMN}$ and the ventrolateral PAG $(r=0.962 ; p=0.00212)$. No other comparisons revealed significant correlations.

A general comparison was made of the time course of labeling between male and female rats. Because of the small sample sizes, statistical comparisons were not possible; however, our analysis 

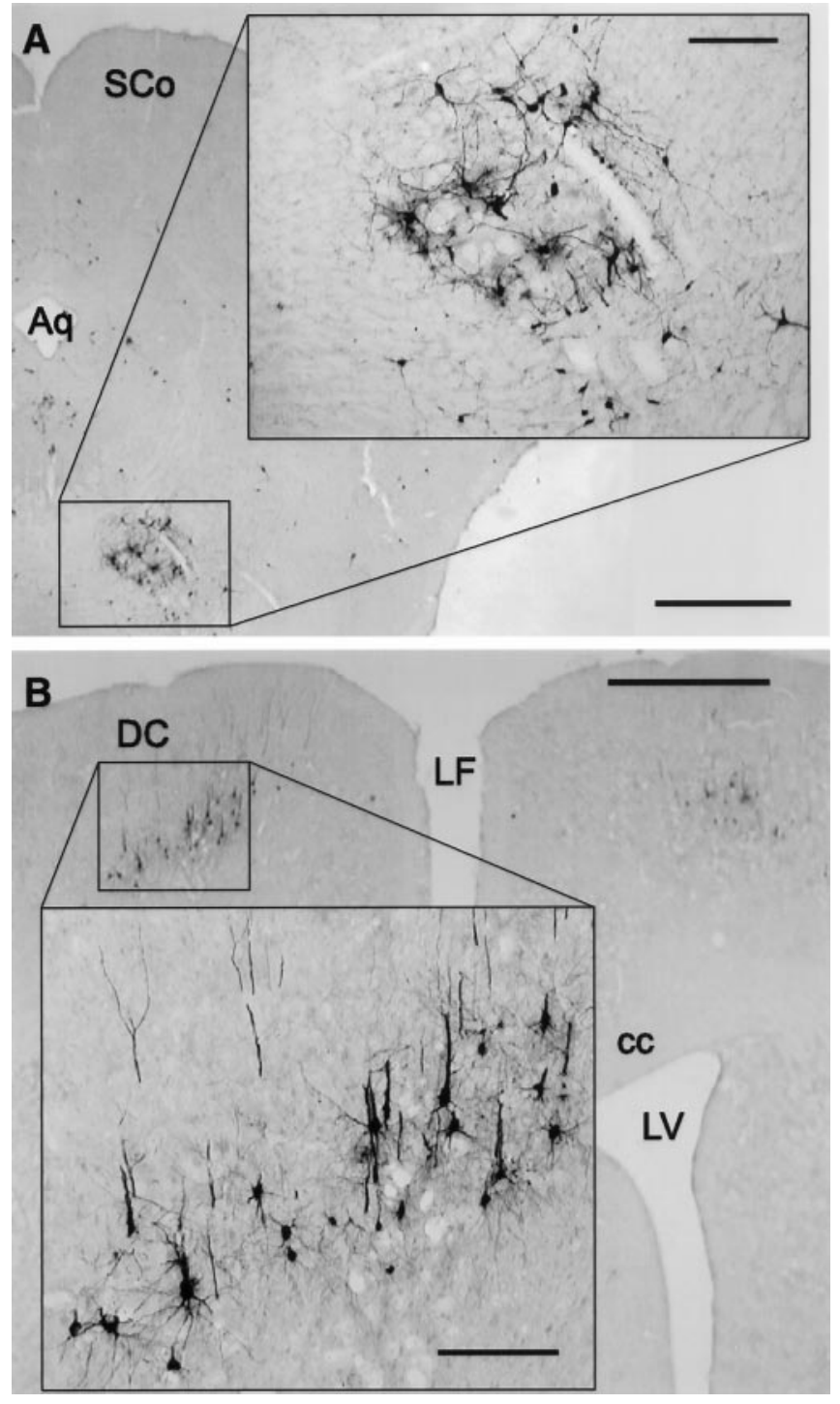

Figure 6. A, Representative micrograph of PRV-immunoreactive neurons in the red nucleus $4.0 \mathrm{~d}$ after PRV injection into the lordosisproducing muscles. Inset, Higher magnification of the indicated area. Scale bars: $1 \mathrm{~mm}$; inset, $200 \mu \mathrm{m}$. $B$, Representative micrograph of PRVimmunoreactive neurons in the dorsal cortex $4.0 \mathrm{~d}$ after PRV injection into the lordosis-producing muscles. Inset, Higher magnification of the indicated area. Scale bars: $1 \mathrm{~mm}$; inset, $200 \mu \mathrm{m}$. Aq, Aqueduct; $c c$, corpus callosum; $D C$, dorsal cortex; $L F$, longitudinal fissure; $L V$, lateral ventricle; Sco, superior colliculus.

did not reveal any gross sex differences in the pattern of virus propagation in either the spinal cord or brain. The number of PRV-labeled cells was similar in the PAG and VMN of male and female rats.

\section{DISCUSSION}

The goal of this experiment was to use PRV to demonstrate serial connectivity between brain areas previously identified as part of the lordosis circuit and to clarify the details of this circuitry. PRV is an $\alpha$-herpesvirus exploited in neuroanatomical tracing studies because of its ability to selectively infect neurons that are synaptically related. In general, the results support serial connectivity among the VMN, PAG, and MRF in the control of lordosis.

Previous applications of this technique have traced neural circuits associated with the sympathetic nervous system (Strack et al., 1989a,b; Strack and Loewy, 1990; Jansen et al., 1993, 1995), parasympathetic nervous system (Card et al., 1990; Nadelhaft et al., 1992), visual system (Card et al., 1991, 1992), reproductive organs (Marson et al., 1993; Marson, 1995; Marson and McKenna, 1996; Papka et al., 1998), and somatic motor systems (Rotto-Percelay et al., 1992; Jasmin et al., 1997). Taken together, these studies reveal that several brain regions become infected with PRV regardless of the injection site (e.g., the area near the A5 noradrenergic cell group, the dorsal parvocellular region of the paraventricular nucleus of the hypothalamus, and the rostral ventrolateral medulla). These structures also were labeled in the present study after injecting PRV into the lordosis-producing muscles. An explanation for such commonality is that all of the injected tissues contain blood vessels innervated by the sympathetic nervous system, through which PRV may infect a common CNS network. In support of this hypothesis, many of the these areas are known to project to the sympathetic preganglionic neurons in the IML (Swanson and Kuypers, 1980; Hosoya et al., 1991). Previous studies suggest that PRV has a predilection for autonomic pathways (Rotto-Percelay et al., 1992). Therefore, one must consider potential autonomic nervous system connectivity when interpreting the presence of PRV in a neuronal population.

In addition to the similarities to results based on other injection sites, several differences also were found. These differences are important because they provide evidence for specificity of the viral labeling for the neural control of these muscles. For example, the present injections infected neurons in areas traditionally associated with motor control, such as the motor area of the dorsal cortex and the red nucleus. These regions were not reported previously to be labeled after PRV injection into visceral targets (Strack et al., 1989b; Card et al., 1990; Nadelhaft et al., 1992).

Although multiple skeletal muscle systems contribute to the full expression of lordosis behavior, our choice of injection site pertains to the dorsiflexion of the spine. Observations of unrestrained, behaving animals have demonstrated the activation of the lateral longissimus during lordosis (Schwartz-Giblin and Pfaff, 1980), and direct stimulation of the transversospinalis, medial longissimus, or lateral longissimus muscles was able to produce dorsiflexion of the spine similar to that seen during mating (Brink and Pfaff, 1980). Injections of the retrograde tracer horseradish peroxidase into the lateral longissimus, medial longissimus, or the L3-L5 level of the transversospinalis labeled neurons in the ipsilateral ventral horn of the spinal cord (Brink et al., 1979). The detection of PRV in motoneurons in the ventral horn of the spinal cord is concordant with previous studies using horseradish peroxidase (Brink et al., 1979) and with the location of motoneuron pools in general (Molander et al., 1984).

Consistent with the proposed lordosis circuit, we observed robust labeling in the MRF, PAG, and VMN. In the MRF, the gigantocellular and paragigantocellular nuclei were detected after survival times of $\geq 3.0 \mathrm{~d}$. These populations have been implicated previously in the control of lordosis. For instance, electrical stimulation of these sites resulted in an EMG response in the lordosis-producing muscles (Femano et al., 1984a). Further analysis of the temporal properties of the EMG response to brainstem stimulation indicated that although stimulation in other areas also produced an EMG response in the muscles, only the stimulation in the gigantocellular and paragigantocellular nuclei had a phaselocked relationship with the EMG recording (Femano et al., 1984b). Moreover, lesions that destroyed both the gigantocellular 


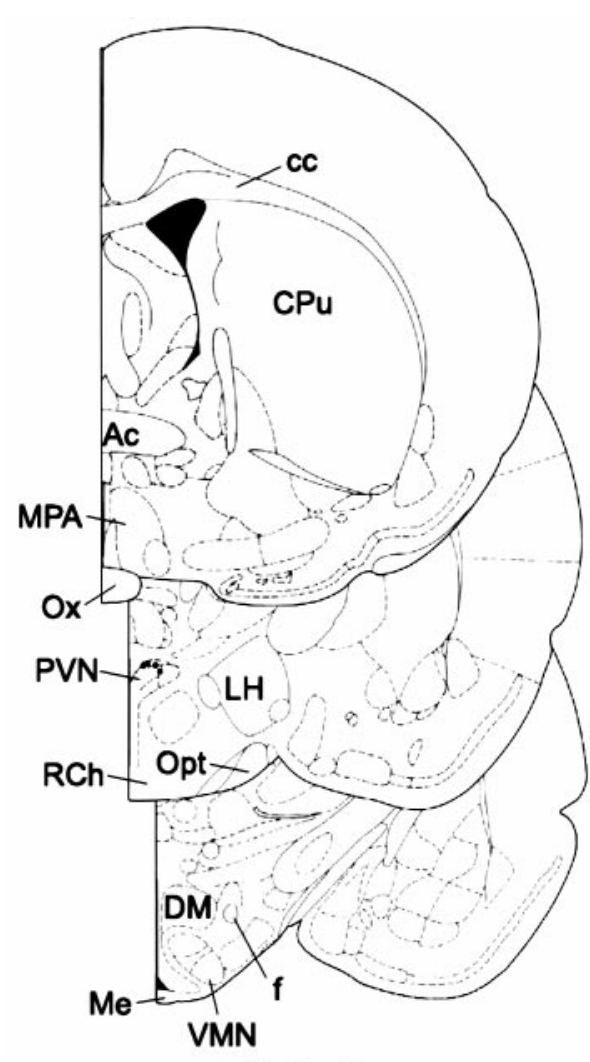

3.0 days

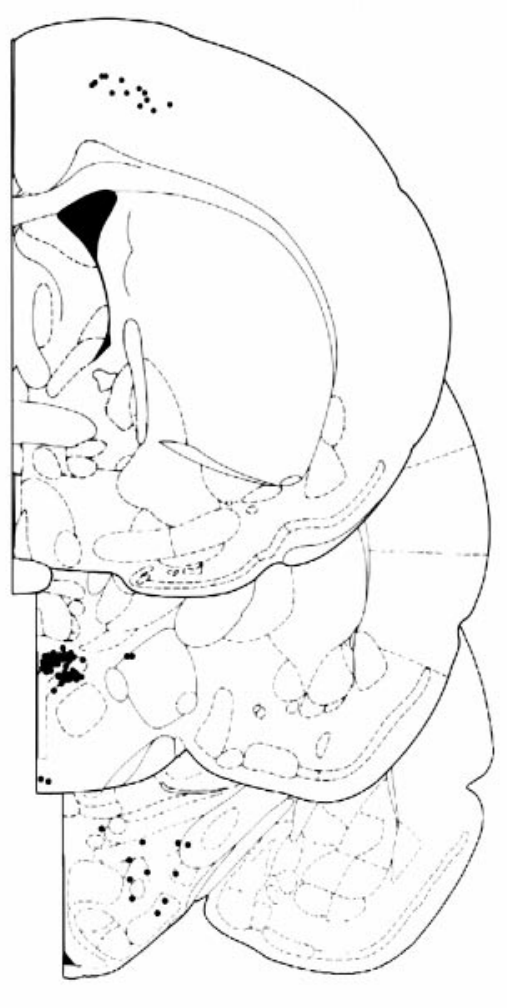

3.3 days

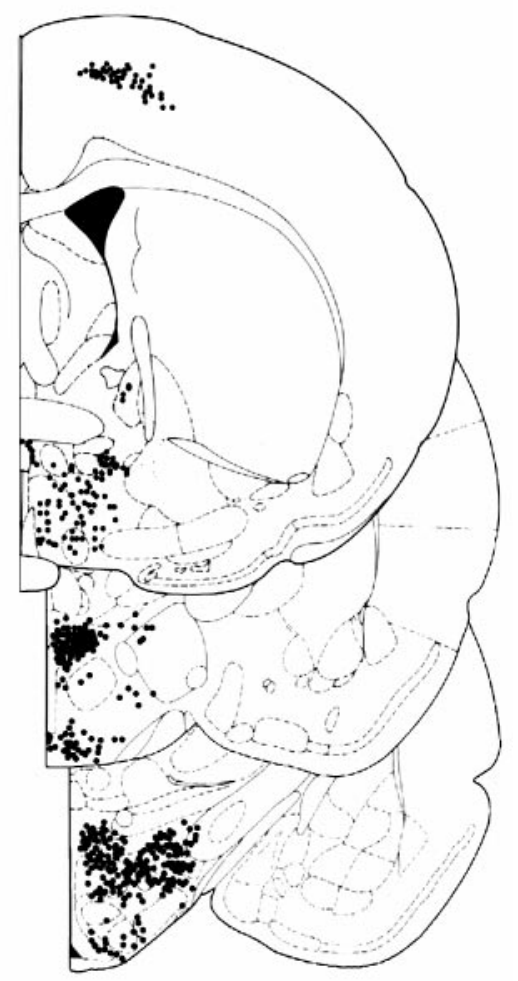

4.0 days

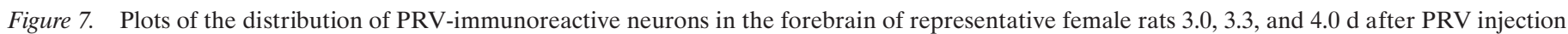

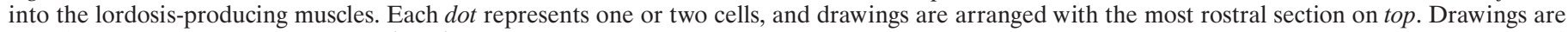

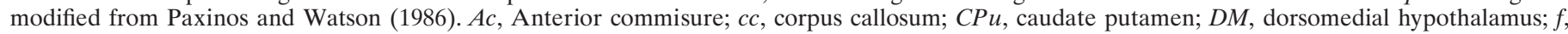

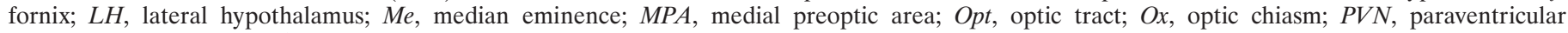
hypothalamic nucleus; $R C h$, retrochiasmatic hypothalamic area.

and paragigantocellular nuclei disrupted lordosis behavior (Zemlan et al., 1983). Thus, the labeling obtained in the MRF with PRV is in accord with previous functional studies of the lordosis pathway. However, it is important to realize that labeling in the MRF is often reported after PRV injection in many targets, and this area is well known to participate in autonomic control, including blood pressure regulation (for review, see Saper, 1995). Future studies will need to disambiguate these two potential sources of PRV labeling in the MRF.

There is ample evidence that the PAG also is an important site for the control of lordosis (Sakuma and Pfaff, 1979a,b; Tetel et al., 1993; Pfaus et al., 1996), and this region was extensively labeled with PRV. However, like the MRF, labeling in the PAG is reported after PRV injection in a variety of targets, and this area is known to participate in the control of blood pressure (Verberne and Guyenet, 1992). It is therefore noteworthy that PAG labeling subsequent to coronary injection of PRV occurred mainly in the dorsal and lateral columns of the PAG (Standish et al., 1995), whereas our labeling was predominantly in the ventrolateral PAG. This is important considering recent studies demonstrating that lesions placed in the caudal ventrolateral PAG, but not in the rostral dorsolateral PAG, disrupt the lordosis reflex (Lonstein and Stern, 1998). Traditional tracers have shown that the PAG projects to both the gigantocellular nucleus and the paragigantocellular nucleus (Beitz et al., 1983). By combining traditional tracing techniques with stimulation-induced EMG recordings, it was demonstrated previously that the PAG sends projections to the MRF areas that elicit an EMG response in the lordosisproducing muscles (Robbins et al., 1990). Additionally, stimulation in the ventrolateral PAG reduces the threshold for stimulation in these medullary sites to produce the same EMG response in the lumbar epaxial muscles (Cottingham et al., 1987). However, this is the first study to anatomically demonstrate multisynaptic connectivity between the PAG and the lumbar epaxial muscles.

The ability of PRV tracing to provide Golgi-like staining of neurons was exploited in the PAG. The present results indicate that PRV-labeled neurons in the PAG are predominantly of a spheroid shape, analogous to the multipolar cells described previously. However, the proportion of multipolar cell types in the PAG visualized by Golgi impregnation was only $20 \%$ (Beitz and Shepard, 1985). The functional significance of these morphological profiles is not known, but the present data provide support for the role of spheroid neurons in the descending projections from the PAG. With additional study, the morphology of the PRV-labeled neurons in the PAG may provide functional clues about the lordosis network.

Abundant evidence has shown that the vl-VMN plays a critical role in the control of lordosis (Mathews and Edwards, 1977; Davis et al., 1979; Pfaff and Sakuma, 1979a,b). Previous studies demonstrated VMN projections to the PAG using traditional tract tracers (Krieger et al., 1979; Beitz, 1982; Morrell and Pfaff, 1982; 

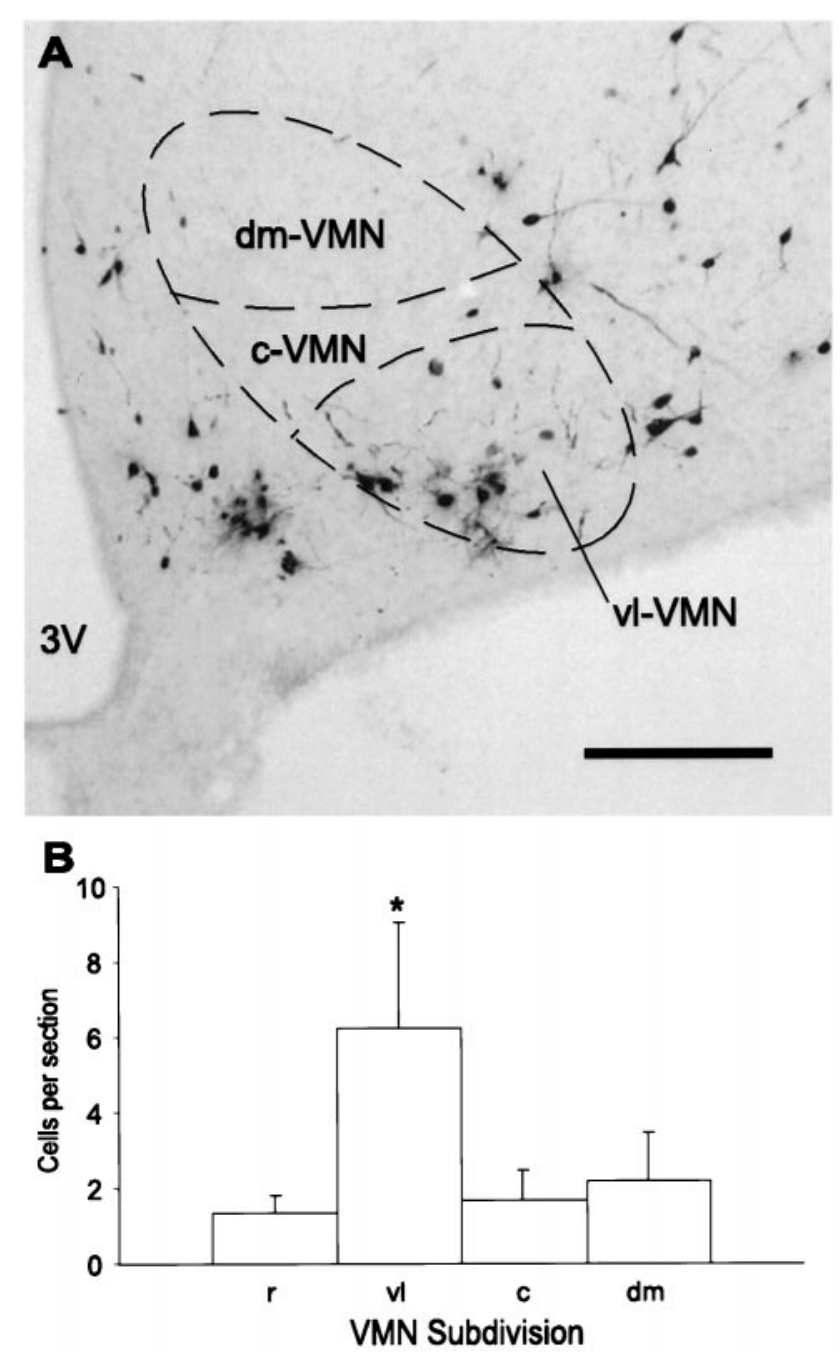

Figure 8. A, Representative micrograph of PRV-immunoreactive neurons in the mediobasal hypothalamus $4.0 \mathrm{~d}$ after PRV injection into the lordosis-producing muscles. Neurons in the VMN are predominantly in the vl-VMN. $3 V$, Third ventricle. Scale bar, $200 \mu \mathrm{m}$. B, Cell counts taken from the rostral $(r)$, ventrolateral $(v l)$, central $(c)$, and dorsomedial $(d m)$ subdivisions of the VMN $4.0 \mathrm{~d}$ after PRV injection into the lordosisproducing muscles. Data were collected from 10-13 sections per animal, and values are shown as mean $\pm \operatorname{SEM}(n=7) .{ }^{*} p<0.05$.

Morrell et al., 1984; Dornan et al., 1990; Akesson et al., 1994). Neurons in the vl-VMN express estrogen receptors (Pfaff and Keiner, 1973), and a subset of these neurons project directly to the PAG (Morrell and Pfaff, 1982; Akesson et al., 1994). Additionally, the expression of FOS in the vl-VMN occurs after mating stimuli (Flanagan et al., 1993; Tetel et al., 1993; FlanaganCato and McEwen, 1995; Polston and Erskine, 1995; Pfaus et al., 1996). In the present study, the vl-VMN contained more PRVpositive cells than the other subdivisions of the VMN. The high correlation between the level of PRV staining in specific columns of the PAG and the rostral and ventrolateral subdivisions of the VMN suggests that these columns transmit virus to the VMN. Previous studies using reproductive targets, including the uterus and clitoris, also identified labeling in the ventrolateral PAG and the VMN (Marson, 1995; Papka et al., 1998). Labeling in the vl-VMN has not been reported with PRV injection into nonreproductive, autonomic targets.

The finding that the general pattern of PRV transmission does not differ between males and females may be partly skewed by the high proportion of labeling associated with sympathetic outflow to blood vessels, where major sex differences would not be expected. However, even in regions implicated in the lordosis reflex, sex differences were not detected in the general pattern of labeling. Further study is needed to explore possible sex differences in the local circuitry and neurochemistry of this pathway.

In conclusion, these studies are the first to indicate that the CNS regions previously implicated in the control of lordosis are serially connected, based on their sequential expression of PRV antigen after PRV injection into the lumbar epaxial muscles. The results also suggest that the ventrolateral column of the PAG may be more involved than other columns, based on the prevalence of labeling. It will now be possible to explore the neurochemistry and local connectivity of PRV-identified, higher-order neurons in this behaviorally relevant pathway.

\section{REFERENCES}

Akesson TR, Ulibarri C, Truitt S (1994) Divergent axon collaterals originate in the estrogen receptive ventromedial nucleus of hypothalamus in the rat. J Neurobiol 25:406-414.

Arendash GW, Gorski RA (1983) Suppression of lordotic responsiveness in the female rat during mesencephalic electrical stimulation. Pharmacol Biochem Behav 19:351-357.

Bandler R, Carrive P, Zhang SP (1991) Integration of somatic and autonomic reactions within the midbrain periaqueductal grey: viscerotopic, somatotopic and functional organization. Prog Brain Res 87:269-305.

Beitz AJ (1982) The organization of afferent projections to the midbrain periaqueductal gray of the rat. Neuroscience 7:133-159.

Beitz AJ (1985) The midbrain periaqueductal gray in the rat. I. Nuclear volume, cell number, density, orientation, and regional subdivisions. J Comp Neurol 237:445-459.

Beitz AJ, Shepard RD (1985) The midbrain periaqueductal gray in the rat. II. A Golgi analysis. J Comp Neurol 237:460-475.

Beitz AJ, Mullett MA, Weiner LL (1983) The periaqueductal gray projections to the rat spinal trigeminal, raphe magnus, gigantocellular pars alpha and paragigantocellular nuclei arise from separate neurons. Brain Res 288:307-314.

Brink EE, Pfaff DW (1980) Vertebral muscles of the back and tail of the albino rat (Rattus norvegicus albinus). Brain Behav Evol 17:1-47.

Brink EE, Morrell JI, Pfaff DW (1979) Localization of lumbar epaxial motoneurons in the rat. Brain Res 170:23-41.

Card JP, Rinaman L, Schwaber JS, Miselis RR, Whealy ME, Robbins AK, Enquist LW (1990) Neurotropic properties of pseudorabies virus: uptake and transneuronal passage in the rat central nervous system. J Neurosci 10:1974-1994.

Card JP, Whealy ME, Robbins AK, Moore RY, Enquist LW (1991) Two alpha-herpesvirus strains are transported differentially in the rodent visual system. Neuron 6:957-969.

Card JP, Whealy ME, Robbins AK, Enquist LW (1992) Pseudorabies virus envelope glycoprotein gI influences both neurotropism and virulence during infection of the rat visual system. J Virol 66:3032-3041.

Cottingham SL, Femano PA, Pfaff DW (1987) Electrical stimulation of the midbrain central gray facilitates reticulospinal activation of axial muscle EMG. Exp Neurol 97:704-724.

Davis PG, McEwen BS, Pfaff DW (1979) Localized behavioral effects of tritiated estradiol implants in the ventromedial hypothalamus of female rats. Endocrinology 104:898-903.

Dornan WA, Akesson TR, Micevych PE (1990) A substance P projection from the $\mathrm{VMH}$ to the dorsal midbrain central gray: implication for lordosis. Brain Res Bull 25:791-796.

Dudley CA, Moss RL (1988) Facilitation of lordosis in female rats by CNS-site specific infusions of an LH-RH fragment, Ac-LH-RH-(5-10). Brain Res 441:161-167.

Femano PA, Schwartz-Giblin S, Pfaff DW (1984a) Brain stem reticular influences on lumbar axial muscle activity. I. Effective sites. Am J Physiol 246:R389-R395.

Femano PA, Schwartz-Giblin S, Pfaff DW (1984b) Brain stem reticular influences on lumbar axial muscle activity. II. Temporal aspects. Am J Physiol 246:R396-R401. 
Flanagan LM, Pfaus JG, Pfaff DW, McEwen BS (1993) Induction of FOS immunoreactivity in oxytocin neurons after sexual activity in female rats. Neuroendocrinology 58:352-358.

Flanagan-Cato LM, McEwen BS (1995) Pattern of Fos and Jun expression in the female rat forebrain after sexual behavior. Brain Res 673:53-60.

Floody OR, Lisk RD, Vomachka AJ (1986) Facilitation of lordosis by estradiol in the mesencephalic central gray. Physiol Behav 37:587-595.

Harlan RE, Shivers BD, Pfaff DW (1983) Midbrain microinfusions of prolactin increase the estrogen-dependent behavior, lordosis. Science 219:1451-1453.

Hosoya Y, Sugiura Y, Okado N, Loewy AD, Kohno K (1991) Descending input from the hypothalamic paraventricular nucleus to sympathetic preganglionic neurons in the rat. Exp Brain Res 85:10-20.

Jansen AS, Farwell DG, Loewy AD (1993) Specificity of pseudorabies virus as a retrograde marker of sympathetic preganglionic neurons: implications for transneuronal labeling studies. Brain Res 617:103-112.

Jansen AS, Wessendorf MW, Loewy AD (1995) Transneuronal labeling of CNS neuropeptide and monoamine neurons after pseudorabies virus injections into the stellate ganglion. Brain Res 683:1-24.

Jasmin L, Carstens E, Basbaum AI (1997) Interneurons presynaptic to rat tail-flick motoneurons as mapped by transneuronal transport of pseudorabies virus: few have long ascending collaterals. Neuroscience 76:859-876.

Krieger MS, Conrad LC, Pfaff DW (1979) An autoradiographic study of the efferent connections of the ventromedial nucleus of the hypothalamus. J Comp Neurol 183:785-815.

Lonstein J, Stern J (1998) Site and behavioral specificity of periaqueductal gray lesions on postpartum sexual, maternal, and aggressive behaviors in rats. Brain Res 804:21-35.

Marson L (1995) Central nervous system neurons identified after injection of pseudorabies virus into the rat clitoris. Neurosci Lett 190:41-44.

Marson L, McKenna KE (1996) CNS cell groups involved in the control of the ischiocavernosus and bulbospongiosus muscles: a transneuronal tracing study using pseudorabies virus. J Comp Neurol 374:161-179.

Marson L, Platt KB, McKenna KE (1993) Central nervous system innervation of the penis as revealed by the transneuronal transport of pseudorabies virus. Neuroscience 55:263-280.

Mathews D, Edwards DA (1977) Involvement of the ventromedial and anterior hypothalamic nuclei in the hormonal induction of receptivity in the female rat. Physiol Behav 19:319-326.

Molander C, Xu Q, Grant G (1984) The cytoarchitectonic organization of the spinal cord in the rat. I. The lower thoracic and lumbosacral cord. J Comp Neurol 230:133-141.

Morrell JI, Pfaff DW (1982) Characterization of estrogen-concentrating hypothalamic neurons by their axonal projections. Science 217:1273-1276.

Morrell JI, Schwanzel-Fukuda M, Fahrbach SE, Pfaff DW (1984) Axonal projections and peptide content of steroid hormone concentrating neurons. Peptides 5:227-239.

Murphy AZ, Ennis M, Rizvi TA, Behbehani MM, Shipley MT (1995) Fos expression induced by changes in arterial pressure is localized in distinct, longitudinally organized columns of neurons in the rat midbrain periaqueductal gray. J Comp Neurol 360:286-300.

Nadelhaft I, Vera PL, Card JP, Miselis RR (1992) Central nervous system neurons labelled following the injection of pseudorabies virus into the rat urinary bladder. Neurosci Lett 143:271-274.

Papka RE, Williams S, Miller KE, Copelin T, Puri P (1998) CNS location of uterine-related neurons revealed by trans-synaptic tracing with pseudorabies virus and their relation to estrogen receptorimmunoreactive neurons. Neuroscience 84:935-952.

Paxinos G, Watson C (1986) The rat Brain in stereotaxic coordinates. Sydney, Australia: Academic.

Pfaff D (1980) Estrogens and brain function. A neural analysis of a hormone controlled mammalian reproductive behavior. New York: Springer.

Pfaff DW, Keiner M (1973) Atlas of estradiol-concentrating cells in the central nervous system of the female rat. J Comp Neurol 151:121-158.

Pfaff DW, Sakuma Y (1979a) Deficit in the lordosis reflex of female rats caused by lesions in the ventromedial nucleus of the hypothalamus. J Physiol (Lond) 288:203-210.

Pfaff DW, Sakuma Y (1979b) Facilitation of the lordosis reflex of female rats from the ventromedial nucleus of the hypothalamus. J Physiol (Lond) 288:189-202.
Pfaus JG, Marcangione C, Smith WJ, Manitt C, Abillamaa H (1996) Differential induction of Fos in the female rat brain following different amounts of vaginocervical stimulation: modulation by steroid hormones. Brain Res 741:314-330.

Polston EK, Erskine MS (1995) Patterns of induction of the immediateearly genes c-fos and egr- 1 in the female rat brain following differential amounts of mating stimulation. Neuroendocrinology 62:370-384.

Richmond G, Clemens LG (1986) Evidence for involvement of midbrain central gray in cholinergic mediation of female sexual receptivity in rats. Behav Neurosci 100:376-380.

Riskind P, Moss RL (1983) Midbrain LHRH infusions enhance lordotic behavior in ovariectomized estrogen-primed rats independently of a hypothalamic responsiveness to LHRH. Brain Res Bull 11:481-485.

Rizvi TA, Murphy AZ, Ennis M, Behbehani MM, Shipley MT (1996) Medial preoptic area afferents to periaqueductal gray medullo-output neurons: a combined Fos and tract tracing study. J Neurosci 16:333-344

Robbins A, Schwartz-Giblin S, Pfaff DW (1990) Ascending and descending projections to medullary reticular formation sites which activate deep lumbar back muscles in the rat. Exp Brain Res 80:463-474.

Rotto-Percelay DM, Wheeler JG, Osorio FA, Platt KB, Loewy AD (1992) Transneuronal labeling of spinal interneurons and sympathetic preganglionic neurons after pseudorabies virus injections in the rat medial gastrocnemius muscle. Brain Res 574:291-306.

Sakuma Y, Pfaff DW (1979a) Facilitation of female reproductive behavior from mesensephalic central gray in the rat. Am J Physiol 237:R278-R284.

Sakuma Y, Pfaff DW (1979b) Mesencephalic mechanisms for integration of female reproductive behavior in the rat. Am J Physiol 237:R285-R290.

Sakuma Y, Pfaff DW (1983) Modulation of the lordosis reflex of female rats by $\mathrm{LHRH}$, its antiserum and analogs in the mesencephalic central gray. Neuroendocrinology 36:218-224.

Saper CB (1995) Central autonomic system. In: The rat nervous system (Paxinos G, ed), pp 107-135. Sydney, Australia: Academic.

Schwartz-Giblin S, Pfaff DW (1980) Implanted strain gauge and EMG amplifier to record motor behavior in unrestrained rats. Physiol Behav 25:475-479.

Standish A, Enquist LW, Escardo JA, Schwaber JS (1995) Central neuronal circuit innervating the rat heart defined by transneuronal transport of pseudorabies virus. J Neurosci 15:1998-2012.

Strack AM, Loewy AD (1990) Pseudorabies virus: a highly specific transneuronal cell body marker in the sympathetic nervous system. J Neurosci 10:2139-2147.

Strack AM, Sawyer WB, Hughes JH, Platt KB, Loewy AD (1989a) A general pattern of CNS innervation of the sympathetic outflow demonstrated by transneuronal pseudorabies viral infections. Brain Res 491:156-162.

Strack AM, Sawyer WB, Platt KB, Loewy AD (1989b) CNS cell groups regulating the sympathetic outflow to adrenal gland as revealed by transneuronal cell body labeling with pseudorabies virus. Brain Res 491:274-296.

Swanson LW, Kuypers HG (1980) The paraventricular nucleus of the hypothalamus: cytoarchitectonic subdivisions and organization of projections to the pituitary, dorsal vagal complex, and spinal cord as demonstrated by retrograde fluorescence double-labeling methods. J Comp Neurol 194:555-570.

Tetel MJ, Getzinger MJ, Blaustein JD (1993) Fos expression in the rat brain following vaginal-cervical stimulation by mating and manual probing. J Neuroendocrinol 5:397-404.

Uphouse L, Caldarola-Pastuszka M, Droge M (1992) 8-OH-DPAT in the midbrain central gray inhibits lordosis behavior. Pharmacol Biochem Behav 43:833-838.

Verberne AJ, Guyenet PG (1992) Midbrain central gray: influence on medullary sympathoexcitatory neurons and the baroreflex in rats. Am J Physiol 263:R24-R33.

Watson RE, Wigand SJ, Clough RW, Hoffman GE (1986) Use of cryoprtectant to maintain long-term peptide immunoreactivity and tissue morphology. Peptides 7:155-159.

Zemlan FP, Kow LM, Pfaff DW (1983) Effect of interruption of bulbospinal pathways on lordosis, posture, and locomotion. Exp Neurol 81:177-194. 